\title{
Penerapan Teorema Titik Tetap pada Sistem Persamaan Integral Volterra
}

\author{
Sagita Charolina Sihombing ${ }^{1}$, Linda Lia $^{2}$ \\ ${ }^{1}$ Jurusan Fisika, FMIPA, Universitas PGRI Palembang \\ ${ }^{2}$ Jurusan Pendidikan Fisika, FKIP, Universitas PGRI Palembang \\ Jl. Jend. A. Yani Lrg. Gotong Royong 9/10 Ulu Palembang \\ ${ }^{1}$ sagita.charolina@yahoo.com, ${ }^{2}$ lindalia_burhan@yahoo.com
}

\begin{abstract}
Abstrak
Penerapan tentang persamaan integral volterra telah berkembang dalam bidang demografi tentang material viscoelastic dan dalam bidang matematika asuransi tentang persamaan yang dibaharui. Sehingga banyak peneliti yang telah mempelajari cara untuk mencari solusi atas persamaan integral tipe ini. Tulisan ini membahas penerapan teorema titik tetap pada sistem persamaan integral volterra linier yang terdiri atas dua jenis pemetaan. Diperoleh bahwa pemetaan kontraktif memberikan syarat kekonvergenan dari suatu sistem persamaan integral volterra. Selain itu, pemetaan kontraktif juga memberikan sarana konstruktif untuk solusi masalah nilai awal sistem persamaan integral volterra dan solusinya dapat diperoleh melalui prosedur iterasi. Perhitungan solusi approksimasi dilakukan menggunakan Matlab $2013 \mathrm{a}$

Kata kunci : teorema titik tetap, sistem persamaan integral volterra, pemetaan kontraktif
\end{abstract}

\section{Abstract}

The application of the volterra integral equation has developed in the field of demography about viscoelastic material and in the field of mathematical insurance about renewed equations. So many researchers have learned how to find solutions to this type of integral equation. This paper discusses the application of fixed point theorem on the system of linear volterra integral equations consisting of two types of mapping. It is obtained that contractive mapping provides convergence requirements of a system of volterra integral equations. In addition, contractive mapping also provides constructive means to solve the initial value of the integral volterra equation system and the solution can be obtained through an iteration procedure. Calculation of approximation solutions is done using Matlab 2013a.

Keywords : fixed point theorem, system of integral volterra equation, contractive mapping

2000 Mathematics Subject Classification: 65J10

Received: 2018-07-21, accepted: 2018-10-31. 


\section{Pendahuluan}

Penerapan tentang persamaan integral volterra telah berkembang dalam bidang demografi tentang material viscoelastic dan dalam matematika asuransi tentang persamaan yang dibaharui. Bentuk umum persamaan integral

$$
x(t)=g(t)+\lambda \int_{a}^{t} K(t, s) x(s) d s
$$

disebut sebagai persamaan integral volterra jenis kedua dimana $K(t, s)$ adalah kernel dari persamaan integral, $0<\lambda<1$, dan $g(t), K(t, s)$ adalah fungsi yang diketahui dan berada pada $R=\{(t, s), a<s<t, a<t<b\}$ sedangkan fungsi $x(t)$ adalah fungsi yang akan dicari.

Sistem persamaan integral volterra yang terdiri dari sejumlah $p$-persamaan diberikan sebagai berikut:

$$
x_{i}(t)=g_{i}(t)+\sum_{k=1}^{m} \lambda_{i k} \int_{a}^{t} K_{i k}(t, s) x_{k}(s) d s
$$

untuk $i=1,2,, p, g_{i}(t)$ adalah fungsi kontinu pada $[a, b], K_{i k}(t, s)$ adalah fungsi kernel yang kontinu pada $R=(t, s), a<s<t, a<t<b$ dan $x_{i}(x)$ adalah fungsi yang akan dicari.

Beberapa peneliti [6],[7] telah mempelajari penyelesaian persamaan integral volterra dengan beberapa motode diantaranya dengan metode dekomposisi adomian, metode Transformasi Laplace dan metode aproksimasi suksesi. Maleknejad \& Torabi dalam makalahnya [2] telah menunjukkan penerapan metode titik tetap dalam menyelesaikan persamaan integral nonlinier volterra-hammerstein. Dari uraian tersebut di atas menarik untuk dikaji tentang teorema titik tetap dan aplikasinya untuk menentukan syarat kekonvergenan persamaan integral volterra linier jenis kedua untuk dua pemetaan.

\section{LANDASAN TEORI}

Berikut ini dibahas sifat pemetaan yang menjamin eksistensi titik tetap pada suatu ruang metrik.

Definisi 2.1. Misalkan $X$ adalah sebuah himpunan yang tak kosong. Suatu fungsi $d: X \times X \rightarrow$ $R$ disebut metrik pada $X$ jika memenuhi sifat-sifat sebagai berikut:

(1) $d(x, y) \geq 0$ untuk setiap $x, y \in X$

(2) $d(x, y)=0$ jika dan hanya jika $x=y$

(3) $d(x, y)=d(y, x)$ untuk setiap $x, y \in X$

(4) $d(x, y) \leq d(x, z)+d(z, y)$ untuk setiap $x, y, z \in X$

Himpunan $X$ bersama dengan metrik d disebut ruang metrik dan ditulis $(X, d)$.

Definisi 2.2. Diberikan ruang metrik $(X, d)$. Pemetaan $T: X \rightarrow X$ dikatakan bersifat kontraktif pada $X$ jika terdapat bilangan riil $k \in(0,1)$, sedemikian sehingga berlaku

$$
d(T(x), T(y)) \leq k d(x, y)
$$

untuk setiap $x, y \in X$.

Selanjutnya, ke-kontinu-an dari pemetaan kontraktif diberikan pada lemma dibawah ini.

Lemma 2.3. Suatu pemetaan kontraktif $T$ di suatu ruang metrik $(X, d)$ adalah pemetaan kontinu.

Bukti. Misalkan $x \in X$. Ambil sebarang $\epsilon>0$, pilih $\delta=\frac{\epsilon}{k}>0$ sehingga untuk setiap $d(x, y)<\delta$ berlaku:

$$
d(T(x), T(y)) \leq k d(x, y)<k \frac{\epsilon}{k}=\epsilon
$$

Karena $x$ sebarang anggota di $X$, maka pemetaan $T$ kontinu di $X$ 
Pemetaan yang memenuhi kondisi kontraktif menjamin eksistensi titik tetap. Hal ini diberikan pada Teorema 2.4 berikut.

Teorema 2.4. Misalkan $(X, d)$ adalah sebuah ruang metrik lengkap dan misalkan $T: X \rightarrow X$ adalah sebuah pemetaan yang memenuhi kondisi kontraktif. Maka T mempunyai titik tetap.

Bukti. Ambil $x_{0} \in X$ dan $x_{1}=T\left(x_{0}\right)$ sehingga dapat dibentuk barisan $\left(x_{n}\right)$ sebagai berikut:

$$
x_{0}, x_{1}=T\left(x_{0}\right), x_{2}=T\left(x_{1}\right)=T^{2}\left(x_{0}\right), x_{n}=T^{n}\left(x_{0}\right)
$$

Akan ditunjukkan bahwa $\left(x_{n}\right)$ adalah barisan Cauchy. Perhatikan bahwa

$$
\begin{aligned}
d\left(x_{m}, x_{m+1}\right) & \left.=d\left(T\left(x_{(}-1\right)\right), T\left(x_{m}\right)\right) \\
& \left.\leq k d\left(x_{(}-1\right), x_{m}\right) \\
& \left.\left.=k d\left(T\left(x_{(}-2\right)\right), T\left(x_{(} m-1\right)\right)\right) \\
& \left.\left.\leq k^{2} d\left(x_{(}-2\right), x_{(}-1\right)\right) \\
& \vdots \\
& \leq k^{m} d\left(x_{0}, x_{1}\right)
\end{aligned}
$$

Oleh karena itu, untuk semua $m, n \in \mathbb{N}$ dengan $m>n$,

$$
\begin{aligned}
d\left(x_{n}, x_{m}\right) & \leq d\left(x_{n}, x_{n+1}\right)+d\left(x_{n+1}, x_{n+2}\right)++d\left(x_{m-1}, x_{m}\right) \\
& \leq k^{n} d\left(x_{0}, x_{1}\right)+k^{n+1} d\left(x_{0}, x_{1}\right)++k^{m-1} d\left(x_{0}, x_{1}\right) \\
& =\frac{k^{n}-k^{m}}{1-k} d\left(x_{0}, x_{1}\right)<\frac{k^{n}}{1-k} d\left(x_{0}, x_{1}\right)
\end{aligned}
$$

Dari pertidaksamaan $(6)$, karena $k \in(0,1)$ dan $d\left(x_{0}, x_{1}\right)$ adalah suatu bilangan positif tertentu, maka ruas kanan dari pertidaksamaan (6) konvergen ke nol ketika $n$ sangat besar. Sehingga mengakibatkan $d\left(x_{n}, x_{m}\right) \rightarrow 0$ ketika $n \rightarrow \infty$. Hal ini menunjukkan $\left(x_{n}\right)$ adalah barisan Cauchy. Karena $X$ lengkap maka barisan $\left(x_{n}\right)$ konvergen di $X$. Misalkan $\lim _{n \rightarrow \infty} x_{m}=u$.Akan ditunjukkan bahwa $u$ adalah titik tetap dari pemetaan $T$. Berdasarkan Lemma 2.3, $T$ adalah kontinu sehingga

$$
\lim _{n \rightarrow \infty} x_{n}=u \rightarrow \lim _{n \rightarrow \infty} T\left(x_{n}\right)=T(u)
$$

Terdapat $x_{n+1}=T\left(x_{n}\right)$

$$
\lim _{n \rightarrow \infty} T\left(x_{n}\right)=\lim _{n \rightarrow \infty} x_{n+1}=T(u)
$$

Hal ini menunjukkan bahwa $T(u)=u$. Jadi, u merupakan titik tetap dari pemetaan kontraktif $T$.

\section{Metode Penelitian}

Metode yang digunakan dalam penelitian ini adalah studi literatur. Pembahasan dilakukan dengan terlebih dahulu mempelajari konsep pemetaan kontraktif pada ruang metrik. Kemudian dipelajari penerapannya untuk menentukan syarat cukup kekonvergenan sistem persamaan integral volterra linier untuk dua persamaan. Untuk menentukan solusi nilai approksimasi atas sistem persamaan tersebut dilakukan perhitungan numerik dengan membuat script metode iterasi menggunakan Matlab 2013a. Selanjutnya dihitung nilai error dari solusi numerik tersebut terhadap solusi eksaknya.

\section{Hasil dan Pembahasan}

4.1. Metode Titik Tetap pada Sistem Persamaan Integral Volterra. Sebelum membahas penerapan teorema titik tetap pada sistem persamaan integral volterra, berikut ini dibahas sifat-sifat ruang metrik terurut dan pemetaan pada ruang metrik terurut.

Selain ruang metrik seperti yang diberikan pada Definisi 2.1, terdapat juga ruang metrik terurut yang didefinisikan pada himpunan bilangan real untuk dua pemetaan. Definisi dari ruang metrik terurut diberikan pada Definisi 4.1 berikut. 
Definisi 4.1. Misalkan $X$ adalah suatu himpunan tak kosong. Maka, $(X, \rightarrow, \leq)$ adalah suatu ruang $-L$ terurut jika dan hanya jika:

(1) $(X, \rightarrow)$ adalah suatu ruang $-L$

(2) $(X, \leq)$ adalah himpunan parsial terurut

(3) $\left(x_{n}\right)_{n \in \mathbb{N}} \rightarrow x,\left(y_{n}\right)_{n \in \mathbb{N}} \rightarrow y$ dan $x_{n} \preccurlyeq y_{n}$, untuk setiap $n \in \mathbb{N} \rightarrow x \leq y$

Jika $(X, d)$ adalah suatu ruang metrik, maka struktur kekonvergenan diberikan oleh metrik $d$ dan $(X, d, \leq)$ disebut sebagai ruang metrik terurut.

Berikut ini diberikan definisi himpunan parsial terurut untuk dua pemetaan di ruang metrik terurut.

Definisi 4.2. Misalkan $(X, \leq)$ adalah himpunan terurut parsial. Dua pemetaan $F, G: X \rightarrow X$ dikatakan menaik lemah jika $F x \leq G F x$ dan $G x \leq F G x$ untuk semua $x \in X$.

Contoh 4.3. Misalkan $X=[1, \infty[\times[1, \infty[$ yang dilengkapi dengan koordinat order, yaitu $(x, y) \leq(z, w) \Leftrightarrow x \leq z$ dany $\leq w$. Misalkan $F, G: X \rightarrow X$ didefinisikan oleh $F(x, y)=$ $(2 x, 3 y)$ dan $G(x, y)=\left(x^{2}, y^{2}\right)$, maka $F(x, y)=(2 x, 3 y) \leq G F(x, y)=G(2 x, 3 y)=\left(4 x^{2}, 9 y^{2}\right)$ dan $G(x, y)=\left(x^{2}, y^{2}\right) \leq F G(x, y)=F\left(x^{2}, y^{2}\right)=\left(2 x^{2}, 3 y^{2}\right)$. Oleh karena itu didapat bahwa, $F$ dan $G$ adalah pemetaan menaik lemah.

Pada bagian ini akan ditunjukkan penerapan pemetaan kontraktif untuk sistem persamaan integral volterra yang terdiri dari dua persamaan integral volterra.

Diberikan sistem persamaan integral yang terdiri dari dua persamaan integral volterra sebagai berikut:

$$
\begin{aligned}
& x(t)=\int_{0}^{t} K_{1}(t, s) x(s) d s+g(t), \quad t \in[a, b] \\
& x(t)=\int_{0}^{t} K_{2}(t, s) x(s) d s+g(t), \quad t \in[a, b]
\end{aligned}
$$

Tujuan pada bagian ini adalah menunjukkan bahwa persamaan (9) mempunyai penyelesaian.

Penyelesaian dari persamaan (9) ditunjukkan melalui teorema di bawah ini.

Teorema 4.4. Perhatikan sistem persamaan integral (9). Jika pemetaan $F, G$ menaik lemah dan misalkan terdapat fungsi kontinu $p:[a, b] \times[a, b] \rightarrow R_{+}$dan sebuah fungsi kontinu kanan dan tak menurun $\phi: R_{+} \rightarrow R_{+}$sehingga $\phi(0)=0$ dan $\phi(t)<t$ untuk $t>0$, sedemikian sehingga

$$
\left|K_{1}(t, s) x(s)-K_{2}(t, s) x(s)\right| \leq p(t, s) \phi(|u-v|)
$$

untuk setiap $t, s \in[a, b] d a n u, v \in R^{n}$ dengan $\left.\sup _{(} t \in[a, b]\right) \int_{0}^{x} p(t, s) d s \leq 1$, maka persamaan (9) mempunyai solusi $x$ pada $[a, b]$.

Bukti. Misalkan $X=C\left([a, b], R^{n}\right)$ dengan norm supremum $\|x\|=\max (t \in[a, b])|x(t)|$, untuk $x \in C\left([a, b], R^{n}\right)$. Perhatikan pada $X$, order parsial didefinisikan oleh $x, y \in C\left([a, b], R^{n}\right), x<y$ jika dan hanya jika

$$
x(t) \leq y(t) \text { untuksebarangt } \in[a, b]
$$

Maka $(X, \leq)$ adalah himpunan order parsial dan $(X,\|\cdot\|)$ adalah ruang metrik lengkap. Selanjutnya untuk sebarang barisan $x_{n}$ di $X$ konvergen ke $x^{*} \in X$, didapat $x_{n}(t) \leq X$ dengan $t \in[a, b]$. Didefinisikan pemetaan $F, G: X \rightarrow X$, oleh

$$
\begin{aligned}
& F x(t)=\int_{0}^{x} K_{1}(t, s) x(s) d s+g(t), t \in[a, b] \\
& G x(t)=\int_{0}^{x} K_{2}(t, s) x(s) d s+g(t), t \in[a, b]
\end{aligned}
$$


Maka, untuk semua $t \in[a, b]$

$$
\begin{aligned}
F x(t) & =\int_{0}^{x} K_{1}(t, s) x(s) d s+g(t) \\
& \leq \int_{0}^{x} K_{2}(t, s)\left(\int_{0}^{x} K_{1}(s,) x() d+g(s)\right) d s+g(t) \\
& =\int_{0}^{x} K_{2}(t, s) F x(s) d s+g(t) \\
& =G F x(t) \\
G x(t) & =\int_{0}^{x} K_{2}(t, s) x(s) d s+g(t) \\
& \leq \int_{0}^{x} K_{1}(t, s)\left(\int_{0}^{x} K_{2}(s,) x() d+g(s)\right) d s+g(t) \\
& =\int_{0}^{x} K_{1}(t, s) G x(s) d s+g(t) \\
& =F G x(t)
\end{aligned}
$$

Sehingga, diperoleh $F x \leq G F x$ dan $G x \leq F G x$ untuk semua $x \in X$. Ini menunjukkan bahwa $F$ dan $G$ menaik secara lemah.

Juga, untuk setiap $x, y \in X$, diperoleh

$$
\begin{aligned}
|F x(t)-G y(t)| & =\left|\int_{0}^{x} K_{1}(t, s) x(s) d s-\int_{0}^{x} K_{2}(t, s) y(s) d s\right| \\
& \leq \int_{0}^{x}\left|K_{1}(t, s) x(s)-K_{2}(t, s) y(s)\right| d s \\
& \leq \int_{0}^{x} p(t, s) \phi(|x(s)-y(s)|) d s \\
& \leq \phi(\|x-y\|) \int_{0}^{x} p(t, s) d s \\
& \leq \phi(\|x-y\|), \text { untuksebarangt } \in[a, b]
\end{aligned}
$$

Oleh karena itu, $\|F x-G y\| \leq \phi(\|x-y\|)$ untuk setiap $x, y \in X$.

4.2. Metode Aproksimasi Sistem Persamaan Integral Volterra. Dengan memilih fungsi awal $x_{0}(t) \in C[a, b]$,sistem persamaan integral volterra dapat diselesaikan dengan proses iterasi sebagai berikut:

$$
\begin{aligned}
& \left(x_{1}\right)(t)=\left(T x_{1}\right)(t)=\int_{0}^{t} K_{1}(t, s) x(s) d s+g(t) \\
& \left(x_{2}\right)(t)=\left(T x_{2}\right)(t)=\int_{0}^{t} K_{2}(t, s) x(s) d s+g(t)
\end{aligned}
$$

Karena $g(t) \in C[a, b]$, maka hal ini dapat dipilih sebagai fungsi awal untuk iterasi tersebut, $\left.x_{(} r, 0\right)=g_{r}(t)$. Karena $T$ adalah pemetaan kontraksi, teorema pemetaan kontraksi memberikan sarana konstruktif untuk solusi masalah nilai awal dalam dan solusinya dapat diperoleh melalui prosedur iterasi. Langkah-langkah penyelesaian sistem persamaan integral volterra diberikan sebagai berikut:

langkah (1): tentukan interval $C[a, b]$, dan jumlah iterasi $n$

langkah (2): input kondisi awal $x_{1}, 0=g_{1}(t)$ dan $x_{2}, 0=g_{2}(t)$

langkah (3): bentuk matriks $\left.x_{(} 1, i\right) \operatorname{danx}_{(2, i)}$ untuk $i=1,2,3,, n-1$

langkah (4): tentukan $x_{1}, 1=x_{1}, 0$ dan $x_{2}, 1=x_{2}, 0$

langkah (5): ulangi proses ini untuk mendapatkan $x_{(1,(i+1))}$ dan $\left.x_{(} 2,(i+1)\right)$ untuk $i=$ $1,2,3, n-1$

langkah (6): hitung nilai error dengan $\left.e^{1}=\mid x_{1}(t)-x_{(} 1, i\right)(t) \mid$ dan $\left.e^{2}=\mid x_{2}(t)-x_{(} 2, i\right)(t) \mid$ untuk $i=1,2,3, n-1$

4.3. Percobaan Numerik. Pada bagian ini dibahas penerapan metode titik tetap untuk dua persamaan integral volterra.

$$
\begin{aligned}
& x_{1}(t)=t+\frac{1}{2} t^{3}+\frac{1}{12} t^{4}-\frac{1}{3} t^{5}+\int_{0}^{t}(t-s)\left(x_{1}(s)+x_{2}(s)\right) d s \\
& x_{2}(t)=t^{2}-\frac{1}{3} t^{3}-\frac{1}{4} t^{4}+\int_{0}^{t} t\left(x_{1}(s)+x_{2}(s)\right) d s, 0 \leq t \leq 1
\end{aligned}
$$

Diketahui solusi eksak $x_{1}(t)=t$ dan $x_{2}(t)=t^{2}$

Dengan memisalkan $X=C\left([0,1], R^{n}\right)$ dan

$$
\begin{aligned}
& F x(t)=x_{1}(t)=t+\frac{1}{2} t^{3}+\frac{1}{12} t^{4}-\frac{1}{3} t^{5}+\int_{0}^{t}(t-s)(x(s)+y(s)) d s \\
& G y(t)=x_{2}(t)=t^{2}-\frac{1}{3} t^{3}-\frac{1}{4} t^{4}+\int_{0}^{t} t(x(s)+y(s)) d s
\end{aligned}
$$


Maka,

$$
\begin{aligned}
F x(t) & =\int_{0}^{x}(t-s)(x(s)+y(s)) d s+t+\frac{1}{2} t^{3}+\frac{1}{12} t^{4}-\frac{1}{3} t^{5} \\
& =\left(\int_{0}^{x}(t)(x(s)+y(s)) d s-\int_{0}^{x}(s)(x(s)+y(s)) d s\right)+t+\frac{1}{2} t^{3}+\frac{1}{12} t^{4}-\frac{1}{3} t^{5} \\
& \leq \int_{0}^{x}(t) F x(s) d s+g(t) \\
& =G F y(t) \\
G x(t) & =\int_{0}^{x} t(x(s)+y(s)) d s+t^{2}-\frac{1}{3} t^{3}-\frac{1}{4} t^{4} \\
& \leq \int_{0}^{x}(t)(x(s)+y(s)) d s+t^{2}-\frac{1}{3} t^{3}-\frac{1}{4} t^{4}-\int_{0}^{x}(s)(x(s)+y(s)) d s \\
& =\int_{a}^{b}(t-s) G x(s) d s+g(t) \\
& =F G y(t)
\end{aligned}
$$

Sehingga, $F x \leq G F y$ dan $G x \leq F G y$ untuk $x, y \in X$. Ini menunjukkan bahwa $F$ dan $G$ menaik lemah. Selanjutnya, ditunjukkan bahwa:

Sehingga,

$$
\begin{aligned}
|F x(t)-G y(t)| & =\mid\left(t+\frac{1}{2} t^{3}+\frac{1}{12} t^{4}-\frac{1}{3} t^{5}+\int_{0}^{t}(t-s)(x(s)+y(s)) d s\right)- \\
& \left(t^{2}-\frac{1}{3} t^{3}-\frac{1}{4} t^{4}+\int_{0}^{t} t(x(s)+y(s)) d s\right) \mid \\
& =\mid\left(t+\frac{1}{2} t^{3}+\frac{1}{12} t^{4}-\frac{1}{3} t^{5}+\int_{0}^{t}(t)(x(s)+y(s)) d s+\int_{0}^{t}(-s)\left(x_{1}(s)+x_{2}(s)\right) d s\right)- \\
& \left(t^{2}-\frac{1}{3} t^{3}-\frac{1}{4} t^{4}+\int_{0}^{t} t(x(s)+y(s)) d s\right) \mid \\
& =\left|\left(t+\frac{1}{2} t^{3}+\frac{1}{12} t^{4}-\frac{1}{3} t^{5}+\int_{0}^{t}(-s)(x(s)+y(s)) d s\right)-\left(t^{2}-\frac{1}{3} t^{3}-\frac{1}{4} t^{4}\right)\right| \\
& =\left|\left(t+\frac{1}{2} t^{3}+\frac{1}{12} t^{4}-\frac{1}{3} t^{5}+\int_{0}^{t}(-s)(x(s)+y(s)) d s\right)-\left(t^{2}-\frac{1}{3} t^{3}-\frac{1}{4} t^{4}\right)\right| \\
& =\left|\left(t-t^{2}+5 / 6 t^{3}+\frac{1}{3} t^{4}-\frac{1}{3} t^{5}+\int_{0}^{t}(-s)(x(s)+y(s)) d s\right)\right| \\
& =\left|\left(t-t^{2}+5 / 6 t^{3}+\frac{1}{3} t^{4}-\frac{1}{3} t^{5}+(x(s)+y(s)) \int_{0}^{t}(-s) d s\right)\right| \\
& =\left|t-t^{2}+5 / 6 t^{3}+\frac{1}{3} t^{4}-\frac{1}{3} t^{5}-(x(s)+y(s))\right| \int_{0}^{t}(s) d s
\end{aligned}
$$

$$
\int_{0}^{t} p(t, s) d s=\int_{0}^{t}(s) d s \leq 1
$$

dan terdapat fungsi yang memenuhi $\phi(\|x-y\|), x, y \in X$.

Oleh karena itu, terpenuhi $\|F x-G y\| \leq \phi(\|x-y\|)$ untuk setiap $x, y \in X$.

Dengan menggunakan metode iterasi, sistem persamaan integral (13) diselesaikan sebagai

$$
\begin{aligned}
\text { berikut: } & \\
x_{1}, 0(t) & =t+\frac{1}{2} t^{3}+\frac{1}{12} t^{4}-\frac{1}{3} t^{5} \\
x_{2}, 0(t) & =t^{2}-\frac{1}{3} t^{3}-\frac{1}{4} t^{4} \\
x_{1}, 1(t) & =t+\frac{1}{2} t^{3}+\frac{1}{12} t^{4}-\frac{1}{3} t^{5}+\int_{0}^{t}(t-s)\left(x_{1}, 0(s)+x_{2}, 0(s)\right) d s \\
& =t+\frac{1}{2} t^{3}+\frac{1}{12} t^{4}-\frac{1}{3} t^{5}+\int_{0}^{t}(t-s)(0+0) d s \\
& =t+\frac{1}{2} t^{3}+\frac{1}{12} t^{4}-\frac{1}{3} t^{5} \\
x_{2}, 1(t) & =t^{2}-\frac{1}{3} t^{3}-\frac{1}{4} t^{4}+\int_{0}^{t} t\left(x_{1}, 0(s)+x_{2}, 0(s)\right) d s \\
& =t^{2}-\frac{1}{3} t^{3}-\frac{1}{4} t^{4}+\int_{0}^{t} t(0+0) d s \\
& =t^{2}-\frac{1}{3} t^{3}-\frac{1}{4} t^{4} \\
x_{1}, 2(t) & =t+\frac{1}{2} t^{3}+\frac{1}{12} t^{4}-\frac{1}{3} t^{5}+\int_{0}^{t}(t-s)\left(x_{1}, 1(s)+x_{2}, 1(s)\right) d s \\
& =t+\frac{1}{2} t^{3}+\frac{1}{12} t^{4}-\frac{1}{3} t^{5}+\int_{0}^{t}(t-s)\left(t+\frac{1}{2} t^{3}+\frac{1}{12} t^{4}-\frac{1}{3} t^{5}+t^{2}-\frac{1}{3} t^{3}-\frac{1}{4} t^{4}\right) d s \\
x_{2}, 2(t) & =t^{2}-\frac{1}{3} t^{3}-\frac{1}{4} t^{4}+\int_{0}^{t} t\left(x_{1}, 1(s)+x_{2}, 1(s)\right) d s \\
& =t^{2}-\frac{1}{3} t^{3}-\frac{1}{4} t^{4}+\int_{0}^{t} t\left(t+\frac{1}{2} t^{3}+\frac{1}{12} t^{4}-\frac{1}{3} t^{5}+t^{2}-\frac{1}{3} t^{3}-\frac{1}{4} t^{4}\right) d t
\end{aligned}
$$

Jika $\left.x_{(} 1, i\right)$ dan $x_{(2, i)}$ dilanjutkan iterasinya, untuk $|t| \leq 1$ barisan tersebut masingmasing akan konvergen ke $x_{1}(t)=t$ dan $x_{2}(t)=t^{2}$.

Berikut ini adalah perbandingan penyelesaian numerik dan penyelesaian eksak: 


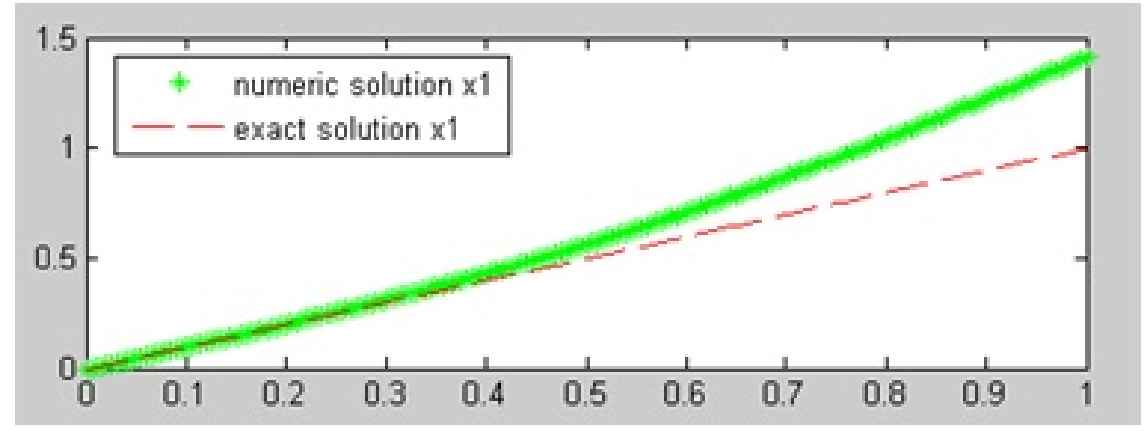

Gambar 1(a). Grafik $x_{1}(t)=t$ dengan $h=0.0$

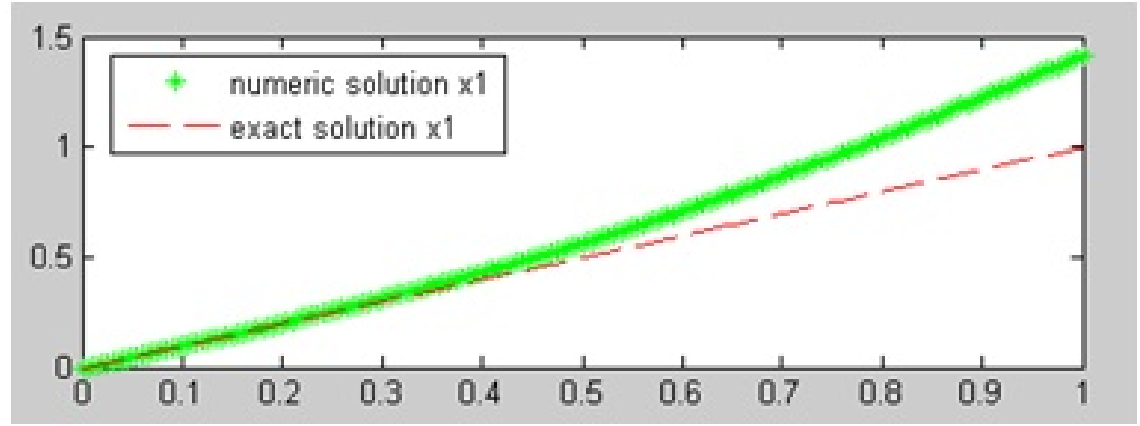

Gambar 1(b). Grafik $x_{2}(t)=t^{2}$ dengan $h=0.01$

Perhitungan error dari penyelesaian numerik dan penyelesaian analitik diberikan di bawah ini.

TABel 1. Tabel Penyelesaian Hampiran dengan $\mathrm{h}=0.01$

\begin{tabular}{||ccccccc||}
$\mathrm{t}$ & $x_{1}$ & $x_{1}$ & Error $x_{1}$ & $x_{2}$ & $x_{2}$ & Error $x_{2}$ \\
\hline 0,00 & 0,00 & 0,00 & 0,00 & 0,00 & 0,00 & 0,00 \\
0,10 & 0,09 & 0,10 & $-0,01$ & 0,01 & 0,01 & 0,00 \\
0,20 & 0,19 & 0,20 & $-0,01$ & 0,04 & 0,04 & 0,00 \\
0,30 & 0,30 & 0,30 & 0,00 & 0,10 & 0,09 & 0,01 \\
0,40 & 0,42 & 0,40 & 0,02 & 0,18 & 0,16 & 0,02 \\
0,50 & 0,55 & 0,50 & 0,05 & 0,30 & 0,25 & 0,05 \\
0,60 & 0,70 & 0,60 & 0,10 & 0,45 & 0,36 & 0,09 \\
0,70 & 0,86 & 0,70 & 0,16 & 0,65 & 0,49 & 0,16 \\
0,80 & 1,03 & 0,80 & 0,23 & 0,90 & 0,64 & 0,26 \\
0,90 & 1,21 & 0,90 & 0,31 & 1,21 & 0,81 & 0,40 \\
1,00 & 1,40 & 1,00 & 0,40 & 1,57 & 1,00 & 0,57 \\
\hline
\end{tabular}

Dari Tabel 1 di atas diketahui bahwa nilai error yang diperoleh dengan solusi numerik untuk $x_{1}$ dan $x_{2}$ relatif kecil dibandingkan dengan solusi eksak.

\section{Kesimpulan}

Dari hasil penelitian diperoleh bahwa sistem persamaan integral volterra linier yang memenuhi sifat pemetaan menaik lemah dan memenuhi kondisi kontraktif memberikan syarat kekonvergenan. Selain itu, solusi yang dihasilkan dengan menggunakan metode iterasi untuk sistem persamaan integral volterra linier memberikan nilai error yang relative kecil jika dibandingkan dengan solusi eksak. 
90 Sihombing dan Lia, JMI Vol 14 No 2 Okt 2018, pp. 83-90,doi:10.24198/jmi.v14.n2.2018.83-90

\section{Ucapan Terimakasih.}

Penelitian ini didanai oleh Kementerian Riset Teknologi dan Pendidikan Tinggi melalui Program Penelitian Dosen Pemula No. 209/E.36/LPPkMK/2018.

\section{DAFTAR Pustaka}

[1] Altun, I \& Simsek, H. Some Fixed Point Theorems on Ordered Metric Spaces and Application, Hindawi Publishing Corporation, Volume 2010, 17 pages; 2010

[2] Maleknejad, K \& Torabi, P. Application of Fixed Point Method for Solving Nonlinear Volterra-Hammerstein Integral Equation. U.P.B. Sci. Bull., Series A, Vol.74, Iss. 1; 2012

[3] Messina, E. \& Vecchio, A. Stability and Boundedness of Numerical Approximations to Volterra Integral Equations. Journal of Applied Numerical Mathematics, Volume 116, pp. 230-237; 2017

[4] Messina, E \& Vecchio, A. Stability and Boundedness of Numerical Approximations to Volterra Integral Equations. Journal of Applied Numerical Mathematics, Volume 116, pp. 230-237; 2017

[5] Nashine, H.K \& Altun, I. New Fixed Point Result for Maps Satisfying Implicit Relations on Ordered Metric Spaces and Application. Journal of Applied Mathematics and Computation. Volume 240, pp 259-272; 2014

[6] ORegan, D. \& Petrusel, B. Fixed Point Theorems for Generalized Contractions in Ordered Metric Space. Journal of Mathematical Analysis and Applications, Volume 341, pp. 1241-1252; 2008

[7] Song, Y \& Kim, H. The Solution of Volterra Integral Equation of the Second Kind by Using Elzaki Transform. Journal Applied Mathematical Sciences, Volume 8, No. 11, pp. 525-530; 2014

[8] Sorkun, HH \& Yalinba, S. Approximate Solutions of Linear Volterra Integral Equation Systems with Variable Coefficients, Journal of Applied Mathematical Modelling, pp. 3451-3464; 2010 